\title{
Aprendizagem baseada em jogos: Uma reflexão sobre o modelo de currículo da Quest to Learn
}

\author{
Lays Rosiene Alves da Silva ${ }^{1}$, Ruy José Guerra Barretto de Queiroz ${ }^{1}$ \\ ${ }^{1}$ Centro de Informática (CIn) - Universidade Federal de Pernambuco \\ \{lras, ruy\}@cin.ufpe.br
}

\begin{abstract}
Quest to Learn (Q2L) is an innovative public school designed to include a games-based pedagogy. Using principles of game design, the whole curriculum becomes dynamic and interdisciplinary allowing the student to live truly immersive learning experiences. The research method to be used in this research is a case study of a qualitative nature. This article is part of a larger study, which is ongoing and seeks to study the learning models in the digital age based games.
\end{abstract}

Resumo. A Quest to Learn (Q2L) é uma escola pública inovadora projetada para incluir uma pedagogia baseada em jogos. Utilizando princípios de Game Design, seu currículo torna-se dinâmico e interdisciplinar fazendo com que o aluno crie experiências de aprendizagem imersiva. O método de pesquisa a ser utilizado nessa pesquisa é um Estudo de Caso de natureza qualitativa. Este artigo faz parte de uma pesquisa mais ampla, que se encontra em andamento e busca estudar os modelos de aprendizagem na era digital baseados em Jogos.

\section{Introdução}

Um grande número de experiências na utilização de tecnologias sociais estão emergindo atualmente na perspectiva de melhorar a aprendizagem. Do ponto de vista pedagógico, jogos e brinquedos digitais oferecem uma nova abordagem para a concepção de aprendizagem. Do ponto de vista tecnológico, jogos digitais empregam tecnologia de computação, multimídia e Internet, enquanto brinquedos inteligentes utilizam chips embutidos e sensores sem fio. Segundo Scaico \& De Queiroz (2013), a escola não deve ser reformada para ser revigorada, ela deve ser repensada dando prioridade à busca pela concepção de espaços de aprendizagem e experimentação, que se utilizem das tecnologias como estrutura, para que os estudantes sejam livres para criar, questionar e aprender com os colegas.

Sistemas de educação progressiva, tais como aqueles propostos por John Dewey e Maria Montessori, podem ser reinterpretados através da lente das tecnologias digitais e de rede para que se possa pensar em aprendizagem escalável. Segundo Thomas \& Brown (2011), podemos identificar três passos para a aprendizagem escalável: Primeiro, a aprendizagem escalável requer um novo tipo de rede de aprendizagem que unifique os recursos que a juventude utiliza dentro e fora da escola. Segundo, sistemas de acreditação usando tecnologias de rede se apresentam como uma outra possibilidade para a aprendizagem escalável. Terceiro, ferramentas avançadas permitem que usuários criem redes de aprendizagem e portanto podem promover a aprendizagem escalável. $\mathrm{O}$ fato é que os jovens estão hoje vivendo num mundo em que eles se engajam em um 
enorme tráfego de conteúdo digital multimodal. Essas ferramentas permitem até que os usuários realizem tarefas como especialistas em redes informais de aprendizagem.

Para Prensky (2012) o sucesso da aprendizagem é a motivação: "um aluno motivado não fica parado. Infelizmente nos dias de hoje a maior parte do conteúdo que precisa ser absorvido pelos alunos não é diretamente motivador para eles". A indústria de jogos movimenta cerca de U\$ 30 bilhões no mundo, e são os jogos a ferramenta para motivação desses jovens. Em 1974, através do jogo Pong, os jogos foram introduzidos no mundo, trazendo a experiência do engajamento: capacidade de manter as pessoas em seus lugares por horas e horas, dia após dia, tentando ativamente alcançar novas metas. É claro que a atitude dos jovens de hoje em relação aos jogos é o oposto da atitude que a maioria deles tem em relação à escola. O que se espera deles é que eles sejam interessados e competitivos, buscando ativamente informações e soluções, o que se vê quando estão jogando.

Nos últimos anos o uso dos jogos instrutivos tem se tornado cada vez mais frequente na escola para a melhoria da aprendizagem. Os videogames têm sido aclamados como um novo paradigma para a educação do século XXI [De Queiroz 2010]. Em uma abreviada autodescrição no web site do Games for Learning Institute, da New York University, o texto nos lembra que se sabe ainda muito pouco o quão bem sucedidos os jogos têm se revelado no papel de ferramenta educativa. É por isso que quando o Institute of Play discute as propriedades de jogos, a intenção é a de se referir a jogos de todos os tipos. Os jogos criam uma necessidade convincente para saber, uma necessidade de perguntar, examinar, assimilar e dominar certas habilidades e áreas de conteúdo. Alguns especialistas argumentam que jogos são, antes de qualquer coisa, sistemas de aprendizagem, e que isso dá conta do sentido de engajamento e entretenimento que os jogadores experimentam.

Foi apostando na capacidade de influência que os jogos provocam nas pessoas, que a game designer Katie Salen fundou em 2007 o Institute of Play. Em parceria com a ONG New Visions for Public Schools, o Institute of Play, criou o projeto "Quest to Learn", que tem como seu propósito criar uma ponte entre o aprendizado escolar e as demandas do século XXI [Salen 2011]. Quest to Learn (Q2L) é uma escola pública inovadora projetada para incluir uma pedagogia baseada em jogos. Utilizando princípios de Game Design - processo de desenvolvimento de jogos que projeta o conteúdo e as regras de um jogo na fase de pré-produção e na fase de produção cria o ambiente, a história e os personagens [Schureiber \& Brathwaite 2009]. Seu currículo é dinâmico e interdisciplinar fazendo com que o aluno crie experiências de aprendizagem imersiva. $\mathrm{O}$ currículo baseado em jogos, torna a aula mais envolvente e participativa, permitindo ao aluno o engajamento social, bem como preparação para enfrentar desafios da vida [Shute, Ventura \& Torres 2012].

Este artigo faz parte de uma pesquisa mais ampla, que se encontra em andamento e busca estudar os modelos de aprendizagem na era digital baseados em Jogos. Na Seção 2 faremos uma reflexão o modelo de currículo da Q2L e por fim apresentaremos as considerações finais.

\section{Quest to Learn}

Fundada em Setembro de 2009, na cidade de Nova York, a Q2L iniciou apenas com 76 alunos do $6^{\circ}$ ano do ensino fundamental [Salen 2011]. Com capacidade total para 560 alunos, a escola tem como objetivo acrescentar uma nova turma até 2015 . O 
precesso de seleção é através de um sistema de loteria aberto e o processo de admissão não depende do desempenho acadêmico anterior. A Q2L não é a única escola que possui seu currículo baseado em jogos, a ChicagoQuest, escola particular, foi fundada em 2011 e segue o mesmo modelo curricular da Q2L. Ambas escolas visam fomentar a curiosidade para a aprendizagem ao longo da vida, bem como compromisso de responsabilidade social e respeito pelos outros e a si mesmo [Shute,Ventura \& Torres 2012].

Foi pensando em avaliar um conjunto de competências-chave que são relevantes e importantes para a Quest to Learn que Shute, Ventura \& Torres (2012) avaliaram durante um período de 20 meses três competências essenciais (pensamento sistêmico, gestão de tempo e trabalho em equipe) para o desenvolvimento dos estudantes. Esse trabalho descobriu que os alunos melhoraram significativamente seus sistemas de habilidade de pensamento e experimentaram uma melhora, embora não significativa, em suas habilidades de gerenciamento de tempo e trabalho em equipe.

Com o objetivo de forçar a criatividade e a resolução de problemas, a cada trimestre, os alunos encontram uma série de desafios cada vez mais complexos chamados de missão. Uma das missões realizadas, esta, na disciplina de Ciências, os alunos ajudam um cientista louco, perdido no interior do corpo humano, a retornar para seu laboratório de pesquisa. $\mathrm{O}$ sistema de navegação que o aluno encontra estimula a relatar como o cientista deverá fazer para chegar em seu destino final por diversos desafios, como se fossem os estágios de um jogo [Salen 2011].

Formado por uma equipe de especialistas em currículo, professores e game designers, o currículo da Q2L é integrado e tem como base as disciplinas Ciências e Matemática, alinhando-se aos padrões do Estado de Nova York. As atividades projetadas por essa equipe, seguem 5 passos: 1-Encontrar um espaço em um problema maduro, 2-Definir as metas de aprendizagem, 3-Interligar as metas para a mecânica do núcleo de aprendizagem, 4-Construir espaços para avaliação e 5-Game Design. O jogo Shortcuts, foi desenvolvido com o propósito de introduzir as crianças para o conceito de distância e permitir-lhes brincar. O jogo acontece da seguinte forma: os jogadores precisam se deslocar de um canto do tabuleiro de jogo para o oposto estimando distâncias em uma grade. As principais mecânicas envolvidas nessa atividade ajudam ao aluno a aprender mais sobre gestão de recursos, estimativas e a encontrar caminhos [Salen 2011]. Outras atividades que complementam o currículo da Q2L, podem ser verificadas na Tabela 1.

Table 1 Atividades Realizadas na Quest to Learn

\begin{tabular}{|c|l|}
\hline Atividades & \multicolumn{1}{|c|}{ Descrição } \\
\hline Mission Lab & $\begin{array}{l}\text { O professor projeta, produz e desenvolve um Game juntamente com } \\
\text { o Game Designer, dentro do conteúdo a ser trabalhado, como } \\
\text { também outros materiais didáticos. }\end{array}$ \\
\hline SMALLab & $\begin{array}{l}\text { O objetivo desta atividade é trazer o aprendizado para a vida, } \\
\text { envolvendo as crianças em atividades físicas de forma divertida, } \\
\text { trabalhos em equipe e resolução de problemas complexos. }\end{array}$ \\
\hline Short Circuit & $\begin{array}{l}\text { O objetivo desta atividade é estimular os alunos a expressarem sua } \\
\text { criatividade e desenvolver habilidades. Caracterizam-se em aulas } \\
\text { extraclasse que ocorrem duas vezes na semana que buscam trabalhar } \\
\text { com mídias digitais, robótica e linguagem de programação. }\end{array}$ \\
\hline
\end{tabular}




\begin{tabular}{|c|c|}
\hline QLink & $\begin{array}{l}\text { É uma Rede Social Educacional, os alunos participam e continuam } \\
\text { interagindo com os colegas e professores mesmo fora da sala de aula, } \\
\text { postando dúvidas e até mesmo ideias de games elaborados por eles } \\
\text { mesmos. }\end{array}$ \\
\hline MobileQuest & $\begin{array}{l}\text { Um acampamento de uma semana, onde os alunos da } 6^{\mathrm{a}} \text { série } \\
\text { exploram técnicas de Game Design e dispositivos móveis. Este } \\
\text { componente compete trabalhar questões como alfabetização digital, } \\
\text { resolução de problemas criativos e colaboração. }\end{array}$ \\
\hline
\end{tabular}

Existem várias formas de avaliações adotadas pela Quest to Learn, para medir o progresso dos estudantes. Uma delas é o exame padronizado que é aplicado em todas escolas públicas de New York. Outra forma de avaliação é aquela em que são elaborados trabalhos ao fim de cada desafio, nos quais os estudantes precisam produzir algo que tenha haver com o conteúdo trabalhado. Isso ajuda professores, pais e até os próprios estudantes a observarem seu progresso.

O Relatório de Progresso do Departamento de Educação de Nova York (NY) informa às famílias sobre os pontos fortes e fracos da escola, enfatizando como os alunos vieram no ano anterior. Este relatório é composto por três seções: $60 \%$ compõe o progresso do aluno, 25\% compõe o desempenho do aluno e 15\% compõe o ambiente escolar. Em cada Seção, os resultados da sua escola são comparados com os resultados de outras escolas que atendem alunos semelhantes. Se uma escola recebe um D ou um $\mathrm{F}$, indica que os alunos desta escola estão demonstrando um ritmo mais lento de aprendizagem e de progresso que os estudantes das escolas similares [Chancelor 2011, 2012, 2013].

De acordo com a Tabela 2, podemos verificar que a Q2L obteve um avanço na Classificação Global no período de 2012-2013. Este avanço se deu devido ao aumento dos pontos extras, pontos estes que são atribuídos às escolas que fazem ganhos excepcionais com alunos com deficiência, alunos de Inglês e alunos com a menor proficiência em toda a cidade. A classificação global é baseada na soma das notas obtidas no progresso do aluno, desempenho do aluno, ambiente escolar, e representa $100 \%$ da pontuação total [Chancelor 2011, 2012, 2013].

Table 2 Classificação Global do Relatório de Progresso da Q2L

\begin{tabular}{|c|c|c|}
\hline Período & Classificação Global & Conceito \\
\hline $2010-2011$ & 42,8 & B \\
\hline $2011-2012$ & 42,8 & B \\
\hline $2012-2013$ & 54,6 & B \\
\hline
\end{tabular}

\section{Considerações Finais}

Em muitas áreas urbanas, o modo predominante de educação pública e, mais importante, o currículo e a pedagogia dessas escolas estão desatualizados. Estes estudantes encontram-se desengajados e desconectados, e não veem propósito em sua educação. As ideias sugeridas pela Q2L são fundamentais para o futuro da educação pública de vários lugares do mundo. Todos os jovens precisam de uma educação de alta qualidade mais do que nunca. O sucesso no século XXI requer um alto nível em matemática, escrita, habilidade de comunicação oral, habilidade para resolver 
problemas, trabalhar como membro de um time, e usar a tecnologia. A preservação da democracia em uma diversidade de países demanda que a escola dê às crianças e aos jovens experiências e conhecimento que contribuirão para competências civis perante a sua vida pública.

Apresentamos aqui uma revisão bibliográfica sobre a aprendizagem baseada em jogos, com vistas a uma apreciação do funcionamento do currículo da Q2L, e da sua eventual escalabilidade - a capacidade de aumento do volume sem afetar a margem de contribuição. O método utilizado para a nossa pesquisa é de natureza qualitativa. Tratase, portanto, de trabalho preliminar que serve de preparação a um Estudo de Caso propriamente dito, que prepara o arcabouço conceitual para a realização do estudo sob o apoio dos conceitos e premissas aqui consolidados.

\section{Agradecimentos}

Registrem-se aqui os melhores agradecimentos ao CNPq pelo auxílio ao nosso grupo de pesquisa sob o projeto "Um Estudo Sobre Aprendizagem na Era Digital e o Uso Efetivo das Tecnologias da Escola ", processo n 486307/2013-1.

\section{Referências}

Chancellor, D. (2011). "Progress Report 2010-11". Departament of Education NYC. http://goo.gl/nkrFtH, Julho.

Chancellor, D. (2012). "Progress Report 2011-12". Departament of Education NYC. http://goo.gl/9qNc6R,Julho.

Chancellor, D. (2013). "Progress Report 2012-13". Departament of Education NYC. http://goo.gl/Oq6Yq1, Julho.

De Queiroz, R. (2010) “Aprender Brincando Significa mais Engajamento”. Os Ventos da Liberdade. http://goo.gl/OvMlX2 , Julho.

Prensky, M. (2012) “Aprendizagem Baseada em Jogos Digitais". Traduzido de: Digital Game-Based Learning. Senac São Paulo. ISBN: 9788539602711

Salen, K. (2011) "Quest to learn: Developing the school for digital kids". Massachusetts Institute of Technology Press books. ISBN 978-0-262-51565-8

Scaico, P. \& De Queiroz, R. (2013). "A educação do futuro: uma reflexão sobre aprendizagem na era digital". Anais do Simpósio Brasileiro de Informática na Educação, Vol. 24, No. 1.

Shute, V., Ventura, M. \& Torres, R. (2012) "Formative Evaluation of Students at Quest to Learn. International Journal of Learning", Vol. 4, No. 1, p. 55-69.

Thomas \& Brown (2011) "A New Culture of Learning: Cultivating the Imagination for a World of Constant Change". CreateSpace Independent Publishing Platform. ISBN: 1456458884. 